\title{
Public geographies through social media
}

\author{
Dialogues in Human Geography \\ 3(I) 56-72 \\ (C) The Author(s) 2013 \\ Reprints and permission: \\ sagepub.co.uk/journalsPermissions.nav \\ DOI: 10.1 | 77//20438206/3486432 \\ dhg.sagepub.com
}

(S)SAGE

\section{Rob Kitchin}

National University of Ireland Maynooth, Ireland

\section{Denis Linehan}

University College Cork, Ireland

\section{Cian O'Callaghan}

National University of Ireland Maynooth, Ireland

\section{Philip Lawton}

Maastricht University, Netherlands

\begin{abstract}
In this paper, we argue that new social media produces new forms of public geography and digital praxis in which the relationship between reader and writer is radically altered and which enables geographers to engage in timely conversation and debate with the public on unfolding issues, and provides new avenues to connect with older forms of broadcast media. Social media can strengthen geographers engagement with the existing fourth estate and forge new relationships with an emerging fifth estate - dynamic, responsive and empowered publics. We illustrate such potentials by drawing on our own experiences of contributing to IrelandAfterNAMA, a collective blog that provides critical analysis of the present crisis in Ireland which has established a regular readership and has led to significant media work (over 500 newspaper articles and radio and television interviews). Such public geography projects are not without their challenges and pitfalls, not least because they alter and challenge the ways in which academics work, communicate and are assessed. Nevertheless, we believe that at the very least their quotidian practices enact what Macgilchrist and Böhmig (2012: 97) term 'minimal politics', creating 'tiny fissures in the mediascape' that inform and engage with wider publics in ways that academic articles rarely do and work to challenge hegemonic formations.
\end{abstract}

\section{Keywords}

digital praxis, fifth estate, minimal politics, public geography, public intellectual, social media

\section{Introduction}

Blogging is a growing feature in the landscape of critical geography. Many geographers now maintain their own personal blogs (research-oriented and

\section{Corresponding author:}

Rob Kitchin, NIRSA, National University of Ireland Maynooth, Maynooth, County Kildare, Ireland.

Email: rob.kitchin@nuim.ie 
otherwise), while journals such as Antipode, Area and Transactions of the Institute of British Geographers ${ }^{1}$ have all launched blogs that mirror and augment the content published within their pages. Blogging is one of a cluster of new modes of communication that has been created by innovations precipitated by Web 2.0. Examples include socialnetworking services (e.g. Facebook), blogs and microblogs (interactive broadcast media, e.g. Blogger and WordPress, Twitter), photo and video sharing sites (e.g. Flickr and YouTube), wikis (open, collectively authored information resources, e.g. Wikipedia), folksonomies (collective tagging of information, e.g. Del.icio.us and Digg) and mashups (open Application Programming Interfaces allowing the merging of data from different sources to create new applications). ${ }^{2}$ The transition to Web 2.0 has dramatically transformed the channels through which information is disseminated and consumed and blurred the relationships between these categories. The rise of academic blogs is indicative of one response to this burgeoning social media movement. Yet, while we are beginning to see the increasing proliferation of blogs within the discipline of Geography, they have not been subject to extensive critical appraisal. Moreover, there is as yet limited discussion concerning how they can be used productively, the extent to which they constitute public geographies, and the challenges posed by their use. In short, there seems to be a tacit assumption that blogs and other social media offer useful avenues for geographers to communicate their work and engage wider publics, but it is unclear as to their wider effects on geographical praxis and how they might generate new modes of enquiry, methodology and forms of political action.

This paper examines the intersection of blogging and public geography by drawing upon our experience of the production of a collective public geographies blog, IrelandAfterNAMA(IAN). Established in November 2009 following the economic crash in 2008 , the contributors to IAN provide critical commentary on the geographies of current economic and social crisis in Ireland. The moniker ' .... after NAMA' refers to the establishment of the National Assets Management Agency by the Irish government, which is essentially a 'bad bank'. Whilst toasted as business solution to the financial crisis, NAMA has socialised the private debts of developers and the Irish banks, accelerating and deepening current and widespread austerity policies (see Kitchin et al., 2012b). Against this background, IAN has sought to provide a spatial and scalar analysis of the crisis in Ireland that productively contributes to the wider public discourse, which has been and continues to be dominated by academic and commercial economists and politicians. In so doing, it has improved the public profile of geography within Ireland leading to significant media work and public engagements, with over 500 newspaper articles, radio interviews and television appearances across its contributors since its inception, and invitations to present to activist groups, professional societies and government departments. In opening new modes of public engagement on and off the web, the blog has created new and unanticipated opportunities for enacting public geographies. The production of the blog, however, has raised a series of issues about the nature of public geography, particularly in the context of the rise of the networked public sphere and the growing influence of social media on forms of political organisation and action. Through a reflection on IAN, in this paper, we address some of the dilemmas and potential created by blogging, which we frame as a form of digital praxis. We consider how the overlapping contexts and processes of Web 2.0 development and public geographies can and might intersect, considering the notion of an emerging fifth estate wherein new social media is facilitating the dissolution of 'the audience' and the creation of dynamic, responsive and empowered publics (Dutton, 2009), and how blogs work to enact, at the very least, what Macgilchrist and Bőhmig (2012) term 'minimal politics'.

\section{Evolving public geographies}

Questions concerning the relevance, responsibility and audience of the work of geographers challenges the discipline and its practitioners to confront what it is they research, for whom and for what ends, and to reflect on how geographical knowledge is produced and the use and value of such knowledges (Kitchin and Sidaway, 2006; Staeheli and Mitchell, 
Table I. Forms of geographical knowledge production and praxis.

\begin{tabular}{ccc}
\hline & Academic audience & Extra-academic audience \\
\hline Instrumental knowledge & Professional geography & Applied (Policy) geography \\
Knowledge & Theoretical/empirical & Concrete \\
Legitimacy & Scientific norms & Cffectiveness \\
Accountability & Peers & Servility \\
Pathology & Self-referentiality & Policy intervention \\
Politics & Professional self-interest & Participatory and public geography \\
Reflexive knowledge & Critical geography & Communicative \\
Knowledge & Foundational & Relevance \\
Legitimacy & Moral vision & Designated publics \\
Accountability & Critical intellectuals & Faddishness \\
Pathology & Dogmatism & Public dialogues \\
Politics & Internal debate &
\end{tabular}

Source: adapted from Burawoy (2005).

2005). Such a self-reflexive exercise has led the sociologist Michael Burawoy (2005) to produce a basic taxonomy of sociological knowledge production and praxis, which he contends applies to any social science discipline (see Table 1 as adapted for geography). Disciplinary praxis, Burawoy argues, is defined principally through the form of knowledge produced (instrumental or reflexive) and its intended audience (academic, extra-academic). Disciplinary debate concerning the relevance and purpose of geographical research, and the forms of political and ethical engagements by geographers with others, is essentially concerned with where geographers position themselves in Burawoy's schema and where they would like the discipline as a whole to be located.

Such debates have been taking place in geography in the Anglophone world since the late 1950s and the quantitative turn in the discipline that sought to create a scientific, professional geography that produced knowledge which would be taken seriously within the wider academic community and beyond. From the late 1960s, and the radical turn within the discipline, there were calls to recast such a professional geography in order to make the discipline more relevant to wider society (Dickinson and Clarke, 1972) and more socially responsible (Prince, 1971) (see Ward, 2006, 2007 for an overview). What transpired was largely, on the one hand, the radicalisation of academic writing and teaching materials (critical geography), and on the other, an engagement with policy makers (applied geography) (Fuller and Kitchin, 2004). Whilst critical geography took time to develop, and went through a period of critique and debate within the discipline in order to establish itself, it is now firmly part of the status quo of geographical labour and praxis. Applied geography, however, has remained somewhat marginal and its relative merits are still the focus of intense debate with respect to the politics and ethics of undertaking policy formulation and implementation and working with state bodies (see Bell, 2007; Hoggart, 1996; Martin, 2001; Massey, 2002; McGuirk and O'Neill, 2012; Peck, 1999; Ward, 2006, 2007; Woods and Gardner, 2011). It is only more recently that participatory and public geography has begun to establish itself as a legitimate and valued form of geographical praxis. Participatory geographies entail a direct and sustained political and social engagement with a community (see Kindon et al., 2007; Pain and Kindon, 2007). Such engagements, largely enacted through social action and activism, reconfigure the research relationship between the academy and communities through the creation of a common social and political contract, and the adoption of emancipatory and empowering forms of praxis. This has been complemented with public geography, such as the People's Geography Project (http://www.peoplesgeographyproject.org/), that seek to produce popular geographical analysis of contemporary issues, translate 
theory and praxis into lay-person's terms, develop school and college curricula and materials, and create linkages with community organisations, labour unions and social movements.

It is interesting that whilst both the instrumental and reflexive elements of the 'academic audience' column of Burawoy's taxonomy (professional and critical geography) are well established and mainstreamed, the two elements of 'extra-academic audience' column (applied and participatory/public geography) are still contentious and much more open to critique and debate. It seems that the discipline has become relatively comfortable with respect to producing instrumental and reflexive geographical knowledges aimed principally at their peers, but is still wrestling with questions concerning the use, value, morals, ethics, work practices and evaluation related to the form of knowledge, legitimacy, accountability, pathology and politics of extraacademic forms of geographical knowledge production and praxis. The issue of academic engagement with wider publics has, in certain contexts, become highly contentious in the last number of years. The introduction and intensification of the research excellence framework (REF) process in the UK, for example, has pushed the notions of 'impact' and 'engagement' centre-stage in debates concerning the value, usefulness and openness of academic work to wider society. The audit culture that the REF system institutionalises has certainly reformulated how many UK academics approach the presentation and dissemination of their work, and has elicited a series of responses and rebuttals that variously seek to redefine or refute 'impact' (see the discussion between Pain et al., 2011, 2012, and Slater, 2012). Similarly, the discussions hosted on the Antipode website concerning the publication by the Participatory Geographies Research Group (2012) of a 'Communifesto for Fuller Geographies' highlight pressing tensions regarding what many view as the growing neoliberalisation of the academy (see also the series of responses, Antipode Foundation, 2012). Within this context, the 'public' dissemination of academic work has become something that is both pertinent and contentious. It is now increasingly important for the purposes of grant applications and assessments that academics are seen to be demonstrating the usefulness of their work to audiences outside the academy. Social media has also had a role to play such endeavours. Research proposals now frequently include plans to produce a blog for the purpose of public dissemination of research outputs, whilst social networking sites such as Twitter and Facebook are used to publicise 'headline' findings.

These concerns, although significant, are nevertheless somewhat peripheral to the thrust of the arguments presented in this paper. Academic blogging is by no means a homogenous activity and, like blogs more generally, academic blogs are created for, and fulfil, a range of purposes. In the case of IAN, as opposed to constituting an attempt on the part of those involved to increase the 'impact' of their research, the initiative was a more 'traditional' enactment of public geography. Rather than seeking to present the findings of a particular research project to a wider public, the initiative attempted to demonstrate how a geographical perspective on current events could contribute to a more nuanced public debates about the unfolding crisis in Ireland. In turn, the blog prompted research and analysis, rather than simply being the vehicle for existing research to be communicated to a wider audience. As such, the starting point was generally with issues that were already of public importance, rather than an attempt to prove the public significance of particular research projects. Our experience with blogging, then, was not prompted by the neoliberalisation and reframing of the academy and present concerns about 'research impact', but rather trying to openly and timely contribute to public debate about the effects of neoliberalism on Irish economy and society. And whilst the blog has certainly had an impact, it is dubious as to whether this can be adequately measured, or is even meaningful, within a particular audit frame, as we discuss more fully below.

Whilst the impetus behind the IAN initiative was thus underlined by a 'traditional' public geography project, the nature of this engagement was fundamentally altered by the mode in which it was presented. As our experience proved, the transferral of a public geography project to the realm of social media transformed the very grounds of the initiative. Burawoy reminds us that knowledge production is reflexive and contingent upon 'different 
types of publics and multiple ways of accessing them' (Burawoy, 2005: 7). However, the imaginary of the public deployed by Burawoy fails to anticipate the disruption caused by new social media and the political response that this precipitates. While Burawoy envisions multiple publics, he views them as coherent 'human categories' that coalesce along distinct lines of identity or class politics. In order to do work in the world, Burawoy argues, sociologists must constitute 'a public that acts in the political arena' by cultivating a 'shared ethos' or 'normative model' that broadly states a sociological position on political and civil society (Burawoy, 2005: 8-15). As such, Burawoy's model, despite appealing to multiple publics, does not envision the fragmented but dynamic and responsive public enabled by new social media. Burawoy essentially presupposes distinct publics for whom sociological knowledge is sliced and parcelled in different ways. However, this fails to account for the radical openness of content accessible to the public sphere that social media enables, not addressing multiple publics in multiple instances, but addressing multiple publics in the same instance.

\section{Communication, politics and the fifth estate}

The multiple, dynamic publics of social media dismantles the structures of the public sphere that Burawoy assumes in his analysis. Indeed, the changing nature of political practice and mass communication is reconfiguring the modes and means by which actors in civil society interface, dialogue and collaborate. Consequently, a paradigm shift seems to be underway leading the creation of the fifth estate (the other four being executive, legislative, judicial and traditional media) involving the dissolution of 'the audience' and the emergence of dynamic, responsive and empowered public through digital networking (Al-Rodhan, 2007; Dutton, 2009). New social media are being used to inform and mobilise diverse publics, cultivate social movements, challenge political and scientific orthodoxy and set political and policy agendas through channels that have very low barriers to entry, are difficult to censor and control and which respond to unfolding events in real time and in some cases precipitate such events (Al-Rodhan, 2007). Moreover, the rapid diversification of media and information platforms, and the migration from newspapers and television to the internet, promotes the development of new online media consumers who access knowledge 'rhizomatically' (Deleuze and Guattari, 1987) by clicking their way through the individualised pathways of news sites, Youtube videos, government reports, tweets, Facebook links and blog posts.

As a consequence, new forms of literacy, new styles of reading, new ways and novel links between software and society permeate current living. In recent times, social media has been located centrally in the context of numerous political events, ranging from panics about privacy, urban riots and national revolutions (Axford, 2011; Baker, 2012; Barnes, 2006). In addition, Web 2.0 has precipitated a range of political aspirations; some commentators for instance have lobbied for the development of Government 2.0, framed as more accountable, open ended and more participatory (Eggers, 2005). It is also the case that in terms of economic activity, the Web 2.0 innovations have been more impactful than e-commerce, as they pull in an increasing share of audiences in areas such as marketing and advertising, media and publishing, disrupting in the process established business models. Empty billboards, regional newspaper closures and reduced revenues for radio and television, together with the ballooning value of social networking sites such as Facebook and Twitter reveal the significance of these events.

There are important historical antecedents to this grand disruption, whereby the relationships between social technologies, authorship and interventions in the public sphere are revealed as consistently in flux. These histories demonstrate that when media technologies change, the political economy and the moral economy of the author may change with it. Foucault's famous essay 'What is an Author' (1987 [1969]) reminds us the concept of authorship has not always existed. Kruase's elaboration of some of the historical shift of authorship in this regard are particularly instructive:

Across genres, the eighteenth and nineteenth centuries mark a transition from art produced in direct 
relationships of patronage to art produced more directly for an expanding public. The legal form of authorship responds to the needs of a group of writers who sought to make a living by writing under these conditions. These shifts coincided with a shift in writers' self-understandings and in readers' expectations. Yet the author is not produced once and for all. For it to continue to exist, it needs to be reproduced again and again, in every generation, but also on a daily basis (Kruase, 2007: 216).

In his consideration of phonography, photography and cinematography, Kittler (1999: 198) notes that 'toward the end of the nineteenth century, the hegemony of the printed word was shattered by the arrival of new media technologies that offered novel ways of communicating and storing data'. A similar scenario now exists in the production of news where ' $\ldots$ the hierarchical, siloed world of mainstream media is being replaced by a new news ecosystem that is ever-dependent on a network of voices and links' (McFadden and Berkowitz, 2009).

It also exists with respect to academia, where social media has the potential to radically restructure the interface between the academy and the wider public. Blogs and Twitter are already being used as public fora in which academics and the wider public engage in dialogue and exchange. Resources such as Wikipedia and OpenStreetMap are co-constructed, crowdsourced sites of knowledge production made by many people, including academic geographers, and involve the re-appropriation and reworking of academic knowledge. It is easy to envisage academic articles becoming the focal points for open dialogue forums where readers are invited to comment on a paper's arguments, much like many newspaper stories, with the authors able to respond. As such, the challenges posed by the fifth estate not only disrupt established channels of dissemination, but engender new forms of politics that require academics to radically rethink their engagement with the public sphere. These new processes are becoming so influential that they necessarily demand reconsideration of the nature of public geography and its modes of intervention in this new arena. This is particularly the case as the rise of networked individualism and networked societies have profound repercussions to the relationships between government and people (Boyd, 2008; Wellman and Haythornthwaite, 2007) and where the contexts of knowledge production and its consumption have become increasingly at issue.

\section{Academic blogging as public geography}

For academics interested in producing and enacting public geographies, blogging provides a range of opportunities within these changing ecologies of readership and authorship. It allows a timely intervention into public debates, and it enables an academic to reach new audiences within the academy, but also beyond, fostering interaction and public dialogue with an audience who might not necessarily engage with the work of academics. This audience can be truly global. The dialogue enabled by blogging provides instant critique and debate with respect to ideas and arguments (anyone can post comments on blog entries). These contacts can also help to source new research material and sharpen or revise lines of argumentation. In some cases, a blog may enable an academic to operate as a public intellectual and develop a profile with respect to policy makers and the media. Blogging can help create new relationships between scholars and activists. Critically, however, whilst in the past the reader was disconnected from the writer, the blog now brings the reader and the author into closer relationships; an interaction that requires fresh understandings of the nature of the relationship and the responsibilities of the author. The blog converts text from a construct (implicitly static, rigid and almost institutional) into an ever-evolving formation of social relations, interconnections and movements.

As part of the rupturing of media and communication technologies, academic blogging plays a role in the restructuring of the established media-technological-political base and its moral and political economy - prestige, posts, promotion and publishing, on the one hand, and the external and dramatic shifts to reading, literacy and information processing, on the other. It could well be that blogging is some kind of intermediary technology (like Betamax) to be superseded later. But in any case, as it 
currently stands blogging forms an important component of the Web 2.0 landscape. As noted by Fuller and Askins (2010), a range of public geographers have already situated themselves within these new media assemblages, contributing on the whole to the development of new but still emergent field of academic/political activity. In addition to blogging, geographers are using other social media such as Facebook and Twitter to share and discuss information and issues and as a medium for conducting research (e.g. see Madge et al. (2009) on Facebook's influence on university student experiences). Consequently, issues arising from the use of social media on geographical knowledge production and the creation of public geographies are growing in number. It remains the case, however, that while there is an emerging recognition of the relative value of these activities, locating blogging in between public individual and knowledge and politics remains in contention.

Academic blogging is characterised by a wide diversity of styles and forms, and whilst they may share similarities, it is not possible to say they share any unified philosophy. It is clear however that blogging does upset traditional academic dissemination by offering a new platform for scholarly exchange (Beer and Burrows, 2007; Price, 2010). Opinions concerning the utility of academic blogging diverge. For some, blogging has been seen as 'career suicide', notably in a context where an academic has no tenure and is not performing with respect to traditional outlets. Hurt and Yin (2006) have considered blogging as a kind of 'extreme sport' due to the risks of reputational damage, and the costs accrued from being diverted from formal and more prestigious academic output. Other commentators have noted, however, that exposure on blogs and other social media dramatically widens readership and engagement. Melissa Terras, for example, suggests that blogging and tweeting about her research papers - which she had placed in an open access repository - significantly increased downloads and citation (Terras, 2012). Other reports are more measured; Kjellberg (2009) concluded from her survey of blogs in the Swedish university system that they do not replace a previous form of communication 'but function as distinct interfaces between four arenas: the university, the research field, the general public, and private life'. With this in mind, the remainder of this paper details our experience of producing a collective public geography blog, IrelandAfterNAMA Through our discussion, we think through some of the questions relating to new social media as it relates to the interface between the university, research and the public sphere.

\section{Digital praxis and impact: IrelandAfterNAMA}

IrelandAfterNAMA (http://irelandafternama.word press.com/) is a collective blog that seeks to provide an informed analysis of the global financial crisis, its history and its present unfolding, in particular, although not exclusively, on the island of Ireland, drawing on social science theory and empirical research. ${ }^{3}$ In particular, it presents a spatial and scalar reading that acknowledges that how the crisis is playing out is spatially uneven and unequal, affecting places in different ways, with its grounding in particular communities the result of processes operating at different scales from the local through to the global. The blog emerged as a concrete outcome of a one-day symposium held in National University of Ireland (NUI) Maynooth on 23 November 2009 entitled 'Geography after NAMA', taking place not long after NAMA had been passed into law (10 September 2009). Effectively operating as a toxic bank, NAMA was charged with acquiring all loans of over $€ 5 \mathrm{~m}$ relating to land and property from six Irish financial institutions and to manage those assets for the benefit of the taxpayer. Assets worth $€ 74 \mathrm{~b}$ at the height of the bubble were transferred into NAMA for a cost of $€ 32 b$ to the taxpayer, thus making the Irish government one of the world's largest managers of land and property loans. In this sense, NAMA marks an important symbolic watershed event in the evolution of the state.

In his AAG presidential address, Alexander B. Murphy (2006) critiqued what he saw as the lack of visibility of geographers in social and political debate. The impetus for the Geography after NAMA symposium was directly related to such a concern; namely that, despite the extensive media coverage devoted to the crisis, the debate was being conducted largely through macroeconomic discourse 
that eschewed social and spatial impacts, critiques and potential solutions. The event, attended mostly by geographers from across Ireland, sought, on the one hand, to discuss how the financial crisis was playing out at local, regional, national and international scales and, on the other, to consider how geography and social sciences more broadly should respond to the crisis in productive ways. A collective blog seemed like an ideal vehicle to try and contribute productively to a public discourse that was dominated by academic and commercial economists and politicians. Indeed, a number of economists had managed to carve out a media profile through their own collective blogs, irisheconomy.ie and progressiveeconomy.ie, along with personal blogs such as ronanlyons.com and davidmcwilliams.com. IAN would provide analysis that extended beyond the economic, creating a useful resource for those wishing to understand the tail-end of the Celtic Tiger period (Ireland's boom period lasting from 1993 to 2007) and Ireland's passage through the present crisis. To some degree, the blog also sought to break the monopoly of 'official social science and policy making' controlled by the Economic and Social Research Institute, a government funded research institute - which largely failed to speak to the crisis, and is often engaged in preparing rationales for neoliberal reforms to social policy. It should also be noted that the blog was launched during a critical juncture characterised by a crisis of faith in mainstream media in Ireland. As Titley (2012), in his analysis of a comparable Irish social media intervention that was orchestrated in the run up to the Government's budget in 2010, suggests, the failure of the mainstream media to pursue adequately critical questions during the Celtic Tiger period and subsequently to question the framing of the 'bailout' opened up a space for media interventions of a different kind. This public appetite for more critical perspectives was instrumental in providing an audience for the IAN blog, ${ }^{4}$ especially given the role of planning and property development.

The blog was created using WordPress on the evening immediately after the symposium. All the participants who had attended the event were provided with the username and password and invited to contribute short opinion pieces, commentaries, book reviews and data analysis. There is no editorial control, and contributors are free to post on whatever topic they wish, signing each post with their own name. As of 16 January 2013, there have been 489 posts on a wide range of issues including the Irish economic model, employment, labour market restructuring, public sector cuts, housing, land rezonings, ghost estates, bank recapitalisation, cross-border shopping, competitiveness, immigration/emigration, public space, diaspora strategy and so on. In total, there have been 387,475 direct views and 1884 comments. There are 276 email subscribers (a mix of academics, journalists, business sector and the public) and 64 wordpress followers. On average, there are between 350 and 600 views per day through the blog site, although, depending on the content published, site views on certain days can be considerably higher (4294 views in the case of our busiest day, but it is not uncommon to have between 700 and 1200 site views on a good day); the number who read the post through a blog reader are unknown. The substantial following the blog garnered in a relatively short period was largely a function of early posts being cited by other influential blogs and coverage in the media, and it was not until early 2012 that we started to use other social media such as Facebook and Twitter to promote posts. The content of blog posts is diverse in terms of length, style and substance. Posts range from short 200 word pieces linking to news stories or data to essays of 2000 plus words that reflect on more complex themes. Due in part to the collective nature of the enterprise, but also contingent upon the types of responses elicited by different events, the style of individual blog posts varies considerably, veering from 'dry' reportage or scientific analysis to polemics verging on the vitriolic. It is not uncommon to be contacted by journalists or organisations in the wake of a post looking for further information.

As Staeheli and Mitchell (2005) suggest, what makes geographical research 'relevant' to any public entails a complex politics incorporating questions including whose relevance and whose geography. In short, relevance is always a question of context. Similarly, Ward (2005: 314-315) suggests the nebulous nature of attempting to gauge how 'policy relevant' any individual or group within the academy actually is, arguing that the notion '.. of informing directly, being named as an author, a contributor, an influence on public policy, is more problematic than it might 
seem at first'. The question of relevance is, thus, a prickly one. Attempting to measure the influence of geographical work on public policy or opinion problematically assumes that we can apprehend a direct causal relationship, whereas in reality, it is much more difficult to pinpoint exactly how, why and when certain ideas take root. In terms of a public geographies project, IAN does nothing to debunk these uncertainties. However, as a case study, it offers some illuminations on this process.

In certain respects, IAN has exceeded initial expectations. It managed to very quickly establish a regular readership interested in a geographical analysis of the crisis in Ireland and elsewhere, which for the most part are new to the work of Irish geographers. It has enabled posters to correspond directly with that readership through the comments section, allowing them to refine and strengthen their analysis and to engage in public debate, and to react quickly to unfolding issues and to publish material in a much more timely fashion. Furthermore, given the timeliness and quality of the material being produced, the blog is becoming a useful pedagogic resource with the posts being used to complement and supplement reading lists on undergraduate and postgraduate courses. It has also enabled some posters to develop a nascent media profile, though that has come with its own challenges which we discuss more fully below. Numerous posts have been picked up by local, national and international media (newspaper, radio, television) and eight posters have undertaking radio interviews and debates on issues covered on the blog on live, national radio and four have appeared on television current affairs programmes. Whilst the majority of media coverage has been in local and national media (including over 180 pieces across the Irish Times, Irish Independent, Irish Examiner, Irish Sun, Irish Mirror and Irish Star and over 70 radio interviews on RTE, Today FM and Newstalk), significantly, the posts on the collapse of the property market have been picked up by international media over 90 times to date (including CNN, New York Times, Wall Street Journal, Bloomberg, Reuters, Guardian, BBC, Der Spiegel, Deutsche Welle, La Figaro and Liberation).

This public profile is not inconsequential. While it is too simple to equate media impact with the number of times IAN content has been cited in the mainstream media, for many posters involved, the blog provided in a short space of time a level of exposure for Irish Geography that alternative forms of public engagement had failed to achieve. Nevertheless, the impact of IAN content on wider public debate is more difficult to estimate. For one, although IAN has garnered a substantial readership, it pales in comparison with that of national print and television media. Consequently, in the event that IAN content does get picked up, the vast majority of those who are exposed to it will be through the mainstream media and not through the blog itself. Moreover, IAN posters have little control over which aspects of their work will be utilised and what 'spin' will be placed upon it. Therefore, while IAN content has been implicated in current public debate in Ireland, such debate has largely been conducted through forums at a step removed from the blog, on which IAN posters can to an extent control in terms of the presentation and interpretation of data, opinion and analysis. The same applies to the dissemination of IAN content through new social media, such as the sharing of IAN posts through online discussion forums, other blogs, Twitter and other mediums.

The correlation between the blog and its public impact is further obscured when it comes to the issue of policy relevance. The media coverage relating to some posts has led to policy changes by central and local government. For example, a nationwide housing survey has been completed to reassess housing vacancy levels in the aftermath of the public debate about the issue, and some of the findings have been debated in the Dail (Irish Parliament) and at local authority council meetings. It is impossible, however, to extrapolate the research findings from their use within media debates and, therefore, to unravel the recommendations of the research from the public pressure emanating from media exposure in their role of affecting policy changes. Thus, the causal relationships remain fuzzy, despite the undeniable positive exposure afforded to Irish social scientists by blogging.

\section{Web 2.0 disruption and challenges of academic blogging}

The new social media platforms enabled by Web 2.0 offer new affordances, and also new disruptions, to 
scholars seeking to engage in public academia. In contrast to Burawoy's (2005) taxonomy, our experience of producing a public geographies blog has not merely involved an attempt to construct a shared ethos for Irish geographers to engage within the political arena, but has unearthed a series of complex questions that challenge our assumptions about the way in which our work is consumed, interpreted and disseminated. Blogging does not only provide a new platform for disseminating academic work but also actively contorts, through iterative and experimental praxis, the material in a way that is relationally contingent upon 'audience participation'. Put simply, blogging forces an academic to think about and present their work in new ways, in part, owing to the very visible mechanisms through which readers (mis)interpret, re-contextualise, appropriate, disseminate and discuss it. This has always been a possible, indeed probable, outcome of publishing, but the modalities and affordances of Web 2.0 do more than extend this into the digital realm. The suite of social media platforms available (including other blogs, Twitter, Facebook and discussion forums) enables readers, in Deleuze and Guattarri's (1987) terminology, to deterritorialise blog posts from their original contexts and reterritorialise them within multiple overlapping assemblages that consistently reframe their meaning. This slippery realm of fluid meaning is the Web 2.0 public sphere that blogs are constitutive of and that public geography must get to grips with. In the following discussion of IAN, we seek to illuminate the nature of this public sphere with the purpose of calling for a form of digital praxis that is cognisant of the various pitfalls and potentialities that befall the academic blogger.

A blog represents a significant commitment of time and energy. In order to maintain and build a reader base, it is necessary to post high-quality material regularly and to be prepared to engage in a timely ongoing debate through the comments. This is a challenge because the labour is usually voluntary (as is the case with IAN) and is thus reliant on the enthusiasm and availability of time of the posters. It is certainly the case that, although IAN notionally has a relatively large number of posters, there is a small cadre of writers who are drafting the vast majority of posts. Thus, more recently, the number of posts has fallen off somewhat, with fewer posters posting less content than during the initial year and a half of the blog. On the one hand, people are busy with other projects, but on the other, there does seem to be an ambivalence about engaging with the mass media in particular (rather than the public). Moreover, with a number of exceptions, the majority of posters have been from one institution, NUI Maynooth, with geographers from other institutions seeming reluctant to begin or continue posting. It is feasible that this is self-reinforcing due to a perception that the blog is predominantly a NUI Maynooth project.

Furthermore, blogging involves a different style of writing and engagement than traditional academic publishing. Posts rarely entail a simple 'extension' of academic writing, being shorter and journalistic in emphasis, and the pieces are often more polemic. They can still use sophisticated theory or employ detailed empirical analysis, but at the same time they need to be pitched at a general audience, with the ideas and writing style open and accessible - for example, many posts involve a more personalised register, using phrases like 'While running for the train this morning I grabbed a copy of Metro Herald ...' or 'I've been asked a few times two related questions ...' to lead into discussions on different topics. Moreover, on a blog like IAN, the pieces are sometimes reactionary, responding to news stories as and when they break (in fact, this is essential if one wants to get into the wider media debate); doing and publishing research becomes a just-in-time process. In many ways then the modalities that propel new social media - immediacy, brevity and reaction - are antithesis to the rigorous and cumbersome apparatus of academic publishing. Indeed, academics are used to spending a considerable amount of time undertaking research, processing data and analysis, reflecting and composing an argument and having a large canvas on which to map out their ideas and findings. Their outputs usually go through several rounds of review, both prior to and then through the refereeing process, enabling extensive edits and the opportunity to refine one's work. Blog posts can go through an editorial process, but it is nonetheless a much more timely process of producing bite-size outputs, than preparing well polished and honed pieces. It takes a degree 
of confidence to publish ideas and analysis to a relatively large and critical audience without following the traditional research and publishing model, the irony being that a great deal many more people are likely to read a piece that took 2 hours to write than one that may have taken 12 months. Especially, as in the case of IAN, when it is known that journalists are reading the blog and picking up comments and analysis for use in the media. This goes back to Staeheli and Mitchell's (2005) comments concerning the multiplicity cloaked within the term 'publicly relevant' and also speak to challenges more broadly posed to academic writing by the dissemination modalities of new social media.

Writing a blog about an emergent topic of interest may also be perceived as a more risky activity in as much as particular ideas or theories can be picked up by future potential interviewees, such as policymakers, as an indication of bias about a particular topic. Thus, while blogging has given academics a voice to debate that which is at times taken for granted within popular discourses, it also runs the risk of further side-lining the academic viewpoint from such a debate in the long-run. The topic discussed in a blog post often does not relate directly to the academic's research interests. Moreover, blog posts do not 'count' as publications on an academic curriculum vitae and, it is thought, will not aid a case for promotion. Thus from a career viewpoint, contributing to a blog might at first appear to be a strategic mistake, particularly for early career academics. While blogging can boost a public profile of an emerging academic and illustrate a commitment to interacting and sharing research with a public audience, it can also give rise to feelings of the opposite, where, as an example, posting loose and unrefined ideas may feel somewhat damaging to the desire to become respected in one's field. Given these various issues, it is unsurprising that some academics can be somewhat reluctant to engage professionally with these technologies.

Of course, there are many positives as well. Blog posts can help build a research profile and networks both in a discipline and beyond. They can lead to media coverage of research. They help to keep a researcher engaged and on top of a particular issue as it unfolds and can be a useful and structured way of undertaking secondary research. They can generate open critique that can help strengthen a project. They can be reworked and extended into longer, more traditional forms of publication, while also aiding the process of learning how to write in a more clear and concise manner. They can form a useful resource of material to supplement course reading lists and to engage in conversation and debate with students. They can help contribute to an institution building a national and international profile, by attracting readers who can then be directed to other resources such as working paper series. And they can help establish collegiality and goodwill within a unit. In other words, they can be used strategically to aid the building of a career and are probably best thought of as complementary to, rather than competing form of, communication to traditional scholarly publishing.

Whilst a blog can be used strategically with respect to a research agenda, one issue that has arisen with respect to IAN has been the blog driving a research agenda, rather than simply being an outlet for one. For example, due to the general and media interests in the posts on housing, and questions posters were being asked on the blog and in interviews, some IAN contributors had to engage in additional research to flesh out their understanding of the Irish housing market and conduct original research that had not been part of their planned workload. The effect was a relatively large unfunded project undertaken over several months leading to a major report, television documentary and significant media work (Kitchin et al., 2010) and several meetings with government departments (including senior civil servants and, in one case, a government Minister), vested interests and data agencies.

Media attention created four other problems to be dealt with. First, certain posts led to a degree of disruption and pressure. For example, the initial posts about housing vacancy and ghost estates generated something of a backlash from some quarters, with the posters receiving a small number of abusive phone calls from vested interests in the construction and associated industries, and the posters were forced to put a media strategy in place (see Kitchin et al., 2012a for an account). As such, the media coverage was both positive (in that it drew attention 
to our work and ideas) and negative (in that it was disruptive and led to a huge amount of scrutiny being focused on the research). As a result of the media attention, posters have had to think carefully about the kinds of material they post to the blog. Initially, the blog was perceived by posters as something of a thought-experiment space to throw out ideas, data analysis and commentary, whereas it was clear that the media were viewing it as completed work for mass consumption. Certainly, we would recommend media training ahead of any substantive engagement with the media, and to consult institutional specialists before trying to publicly defend against vested interests. Second, the data, analysis and conclusions from some posts were being used to critique agencies (e.g. Department of Environment, Community and Local Government and local authorities) with which the posters had ongoing research relationships. They therefore had to negotiate a quite delicate situation of trying to critique in public the policy and actions of bodies for whom they were undertaking other research. Third, the media coverage highlighted that the posters had been publishing derived data that broke the terms of a data license held between the university and a data provider. They had to retrospectively negotiate with the data provider and assure them that this would not happen again. Indeed, it is clear that there are a number of issues concerning intellectual property issues and the posting of copyrighted material that academic bloggers need to be mindful of. Which brings us to the fourth issue, the relationship between individual blogger and his/her home institution. Whilst IAN bloggers have not experienced this issue, we have spoken to others bloggers where the tension between individual freedom of speech and institutional control and oversight has arisen. For institutions, there is an issue of managing its intellectual property rights and its public relations, especially if the blog material is controversial or may attract legal action (in the case of legal action is an academic blog personal or institutional?). One solution with respect to collective blogs is to consider using an editorial procedure such as appointed editors or editorial board that vet posts (for content and writing competence) prior to publishing. However, this may prove difficult to implement in as much as it goes against the often individualistic and reactionary nature of blogging.

A blog also brings the academic into direct contact with the public and involves an implicit contract of engagement and community building, especially through the comments. It is therefore important that time and effort is taken to build a relationship with the audience, though this has its own challenges. For example, some discussions can tend towards being quite confrontational, especially when commenters have totally opposing views on a topic. Some comments can be patronising or abusive or long rants. Moreover, at times, it was hard to discern the source of particular comments due to the possibility of false or multiple identities. This raises questions about the nature of the 'public' within social media. Such experiences, while at times difficult to accept, do however provide important reminders of the nature of academia. The process of presenting findings to a public audience, which may not be as receptive to the particular lines of argument employed within academia, provides a worthwhile reminder of our position in the world. Thus, any naively held beliefs that our 'enlightened' vision of society will be adopted are very often soon rejected under the weight of real-life situations and embedded perspectives. Furthermore, some readers can misinterpret the work and come to erroneous conclusions. Some members of the public expect academics, as researchers funded by the taxpayer, to undertake their pet projects for them. Some readers can take the work and repost it on another forum where a parallel dialogue can take place. For example, some of the maps and data posted on IAN have been reposted on the discussion forum websites propertypin.com and politics.ie, where they were reinterpreted and discussed. Parts of other posts have appeared on semi-private forms of social media, such as Facebook, where they have been deliberately misquoted so as to uphold a counter-argument. This, however, requires a nuanced form of analysis. That publicly available material can be re-appropriated and reinterpreted as not something unique to social media, though it does become much easier and provides fresh challenges such as the proliferation of content across social media channels making it difficult to track and provide counter-discussion. None of these 
issues have been easy to deal with and we have had to formulate collective decisions as to how to resolve amicably without resorting to censorship or confrontation. One potential solution we have heard of is a reader's charter that sets out expected conduct of both posters and readers.

One final issue concerns the long-term maintenance of a blog, and especially the resources that are gathered and links to other sites. IAN does provide an archive of sorts for data analysis and commentary, and links to relevant media coverage and policy documents. Other academic blogging sites, especially from the humanities, often contain scanned pages from old pamphlets and leaflets, or old photographs from personal collections. At present, few of these sites have any explicit archiving policy in place to maintain the resource, and yet most blogs only have a relatively short lifespan of a handful of years. The danger is that over time the valuable material assembled will be lost. In addition, links can die and need to be maintained to preserve integrity of the resource.

\section{Conclusion}

Writing about the impact of his use of a newly purchased typewriter, Nietzsche made an observation that deserves close reading for contemporary social media theorists. In a letter to a friend, he wrote, 'our writing equipment takes part in the forming of our thoughts' (Nietzsche, 2005). The writing tools provided by new social media conduits both afford and necessitate new modes of writing and communication. Furthermore, this software, and the affordances it can accommodate require a re-evaluation of the established identity of the author or 'scholar', as the boundaries of authorship and text can be disassembled by the influence and interventions of readers and commentators in social media based systems. Reflecting on this mode of communication, and their possibilities for political action which as Kittler notes were historically addressed by the Avant Garde in their artistic reflections on typewritters, gramophones and editing tables in the 1920 s and 1930s - presents a new critical location for public geography, which cannot be ignored (Kittler, 1999).
In this paper, we have explored the role of blogging as an element of this new critical location, and addressed the emergent forms of digital praxis involved in the production of public geography in Ireland. On the basis of our experience, it is impossible not to conclude that public geographers need to negotiate new affordances and critical locations to address the political potential of the fifth estate and come to a realistic and knowledgeable understanding of the new modes of communicating research, supporting participation and advocating for change embedded in these developments, which have rendered the public sphere, as envisioned by Burawoy (2005), anachronistic. Whether or not geographers actively engage with new social media, these conduits form an integral component of the restructured public sphere. The emergence of the fifth estate and the multiple modes through which this assemblage operate demands on going consideration which suggests that digital praxis must involve a dialogue between being technologically savvy, politically astute as well as increasingly aware of the diverse and contingent sociological impacts of digital interventions in private and public life (Baym and Boyd, 2012). Additionally, at the level of skills and competencies, there is perhaps some merit in engaging, and to a degree radicalising, the foundational principles of Digital Humanities, where a vision of new forms of scholarship and new modes of production and communication of knowledge are arguably more advanced in their conceptualisation than in the social sciences (Jenkins, 2009). But given the continuous development, and at times unexpected outcomes, in this domain, to a degree it is not possible to anticipate fully the competencies involved, except to say, the cultivation of openness and innovation seems to be at premium. Yet, in terms of defining a critical location for this digital praxis, it is clear that curating public geography, managing digital artefacts and engaging publics need careful estimation as to it limits and potential.

Certainly, the benefits of blogging in enhancing scholarship and teaching, promoting research and engaging the media are clear. IAN has paid dividends to its makers, to our students and has played in part in informing the debate about the outcomes of the economic crash in Ireland to the public at 
large. However, it must also be realised that one blog will not change the world alone, and that wider dissemination or participation in research and advocacy does not necessarily translate into political action or policy change. In this regard, the debate to the specific modes and impacts involved in the use of these new social technologies within media studies and political science are also worth taking into account. In a recent paper on the contribution of blogging to public political debate, Macgilchrist and Böhmig (2012) make the case for viewing the potential of blogging in terms of 'minimal politics'. Blogs are generally criticised for their failure to transcend their limited audiences and, therefore, challenge the dominant neoliberal agenda of the mainstream (hegemonic) media. However, rather than seeing blogs as irrelevant to public political debate, Macgilchrist and Böhmig see them as active parts of an assemblage of 'minimal politics'.

\begin{abstract}
Democracy, in this sense, is not only about broadening participation in public debate, it is also about creating gaps in what can otherwise appear to be a hegemonic formation. Through the strategies - perhaps explicit, perhaps implicit - of rebutting, reflecting and re-articulating ... [blogs] have torn tiny fissures in the mediascape. ... The constant ripping which occurs in the blogosphere, and perhaps also in other spaces of media production, means that 'familiar rituals of the hegemonic formation' are dislocated (Marchart, 2010: 324) and ensures that democracy - understood as practices of conflict and disagreement - is enacted on a daily basis. ... Blogs contribute to the apparently mundane stabilization and destabilization of the existing constellation, and can thus be considered emphatically political. These quotidian practices are, in our opinion, what now require further scholarly attention (Macgilchrist and Bőhmig, 2012, 97).
\end{abstract}

Blogs do not usher in seismic shifts in perception but shoot tiny arrows in the media behemoth that, in combination with those of other counter-hegemonic voices, open up small rips through which change can be effected. As noted by Hannah Arendt (1958), it is precisely this quality of the public sphere to support and create effective political dialogue that generate political efficacy with society. Blogs offer their participants the capacity for agency, and channel their politics and identities together through free speech and persuasion. As a form of public geography, it is within this broader understanding of the public sphere and through the creation and exploitation of fissures made by interventions that blogging must operate. Our experience with producing IAN coincides with such a perspective. While the emergence in Ireland of blogs that comment on and critique the unfolding crisis has not dramatically altered the mainstream media landscape, as our preceding discussion of IAN has demonstrated, it has nevertheless created new openings and new voices that have shifted the scope of the debate on certain issues, at times leading to discernible policy change. Such observations testify to a certain democratisation of the media landscape enabled by Web 2.0; small, quotidian digital actions can have a 'say' in public political discussion. But it is their very quotidian nature that also testifies to the limitations of such democratic media practices within the public sphere. The movement from concentrated 'old media' towards the dispersed field of social media has deterritorialised the dissemination of media content and opened the door to a potentially infinite flood of information, opinion and conjecture. It may even be the case that these multiple, often competing voices, can have the effect of diluting collective political action. What ultimate effect this will have on the political landscape remains to be seen, but the advent of new social media clearly demarcates a juncture that has reformulated the public realm. This leads us to recall the formulation devised by David Livingstone (1992) that when examining the histories of geography its best to remember that 'geographical ideas are worldly, tangible things created and produced at the interface of social, political and intellectual life'. In this sense, in the context of the fifth estate, the praxis of public geography is set for change - not so much a Brave New World, perhaps, but a new world nevertheless.

\section{Notes}

1. Antipode's blog is at http://antipodefoundation.org/ and Area and Transactions share a blog at http:// blog.geographydirections.com/

2. This is not to deny that there were an array of social spaces and self-governing participatory online 
activities during the Web 1.0 era, such as multi-user domains, mailing lists, bulletin boards and Usenet newsgroups, but rather to acknowledge that there are a raft of new media forms being produced and a general shift towards all forms of the Internet becoming more interactive and participatory.

3. The aim of IAN is to provide a space for Irish geographers and other social scientists to contribute to public discussion. Whilst the authors of the current article have all played a role in the production of the blog, it is a collective endeavour dependent upon the energy and commitment of many individuals. Since its inception in September 2009, the following have contributed posts: Delphine Ancien, Brendan Bartley, Mark Boyle, Proinnsias Breathnach, Mary Corcoran, Caroline Creamer, Declan Curran, Gavin Daly, Anna Davies, Aoife Dowling, Ronan Foley, Alistair Fraser, Mary Gilmartin, Ainhoa González, Jane Gray, Justin Gleeson, Rory Hearne, Adrian Kavanagh, Karen Keaveney, Sinéad Kelly, Rob Kitchin, Philip Lawton, Denis Linehan, Andrew MacLaran, Marie Mahon, Des McCafferty, Eoghan McCarthy, Devid Meredith, Niamh Moore, Enda Murphy, Cian O'Callaghan, Eoin O’ Mahony, Sean O'Riain, Michael Punch, Jan Rigby, Chris Van Egeraat, Cormac Walsh and John Watters.

4. Indeed, this period was characterised by an unprecedented flourishing of blogs that offered alternative perspectives on the crisis to those of the mainstream media. IAN was just one of a range of such blogs. Other prominent examples include: Namawinelake http://namawinelake.wordpress.com/; The Story http://thestory.ie/; Notes on the Front http://notesonthefront.typepad.com/ and Crisis Jam http://politico.ie/crisisjam.html (see Titley, 2012 for a discussion on the latter). IAN's geographical focus, however, gave the blog a distinct identity within this emerging social media landscape. Moreover, the crisis in Ireland, in that it was bound up in the crash of a property bubble, was also inherently geographical, thus providing a clear rationality for the need for a geographical analysis (see Kitchin et al., 2012b).

\section{References}

Al-Rodhan NRF (2007) Emergence of Blogs as a Fifth Estate and Their Security Implications. Geneva, Switzerland: Editions Slatkine.

Antipode Foundation (2012) Symposium on the participatory geographies research group's 'communifesto for fuller geographies: towards mutual security', http:// antipodefoundation.org/2012/10/15/symposium-on-theparticipatory-geographies-research-groups-communifesto-for-fuller-geographies-towards-mutual-security/ (accessed 12 January 2013).

Arendt H (1958) The Human Condition. Chicago, IL: University of Chicago Press.

Axford B (2011) Talk about a revolution: social media and the MENA uprisings. Globalizations 8(5): 681-686.

Baker SA (2012) From the criminal crowd to the "mediated crowd": the impact of social media on the 2011 English riots. Safer Communities 11(1): 40-49.

Barnes SB (2006) A privacy paradox: social networking in the United States. First Monday 11(9), http:/firstmonday.org/htbin/cgiwrap/bin/ojs/index.php/fm/article/view/1394/1312 (accessed 8 October 2012).

Baym NK and Boyd D (2012): Socially mediated publicness: an introduction. Journal of Broadcasting and Electronic Media 56(3): 320-329.

Beer D and Burrows R (2007) Sociology and, of and in Web 2.0: some initial considerations. Sociological Research Online 12(5), www.socresonline.org.uk/12/ 5/17.html (accessed 8 October 2012).

Bell D (2007) Fade to grey: some reflections on policy and mundanity. Environment and Planning A 39: 541-554.

Boyd D (2008) Why youth social network sites: the role of networked publics in teenage social life. In: D Buckingham (ed) Youth, Identity, and Digital Media. Cambridge, MA: MIT Press, pp. 119-142.

Burawoy M (2005) For public sociology. American Sociological Review 70: 4-28.

Deleuze G and Guattari F (1987) A Thousand Plateaus: Capitalism and Schizophrenia (trans B Massumi). Minneapolis, MN: University of Minnesota Press.

Dickinson JP and Clarke CG (1972) Relevance and the 'newest geography'. Area 3: 25-27.

Dutton WH (2009) The fifth estate emerging through the network of networks. Prometheus: Critical Studies in Innovation 27(1): 1-15.

Eggers WD (2005) Government 2.0: Using Technology to Improve Education, Cut Red Tape, Reduce Gridlock, and Enhance Democracy. New York, NY: Rowman and Littlefield Publishers.

Foucault M (1987 [1969]) What is an author? In: V Lambropoulos and DN Miller (eds) Twentieth-Century Literary Theory (pp. 124 -142). Albany, NY: State University Press of New York. 
Fuller D and Askins K (2010) Public geographies II: being organic. Progress in Human Geography 34: 654-667.

Fuller D and Kitchin R (2004) Radical theory/critical praxis. In: D Fuller and R Kitchin (eds) Radical Theory, Critical Praxis: Making a Difference Beyond the Academy? Praxis E-Press, pp. 1-20.

Hoggart K (1996) All washed up and nowhere to go? Public policy and geographical research. Progress in Human Geography 20: 110-122.

Hurt C and Yin T (2006) Blogging while untenured and other extreme sports. Washington University Law Review 84: 135-1256.

Jenkins H (2009) Confronting the Challenges of Participatory Culture Media Education for the 21st Century. Boston, MA: MIT Press.

Kindon S, Pain R, and Kesby M (2007) Participatory Action Research Approaches and Methods: Connecting People, Participation and Place. London, UK: Routledge.

Kitchin R, Gleeson J, and Dodge M (2012a) Unfolding mapping practices: a new epistemology for cartography. Transactions of the Institute of British Geographers. Epub ahead of print 14 August 2012. DOI: 10 1111/j.1475-5661.2012.00540

Kitchin R, Gleeson J, Keaveney K, and O'Callaghan C (2010) A haunted landscape: housing and ghost estates in post-celtic tiger Ireland. NIRSA Working Paper Series 59, http://www.nuim.ie/nirsa/research/documents/WP59-A-Haunted-Landscape.pdf (accessed 13 October 2012).

Kitchin R, O'Callaghan C, Boyle M, Gleeson J, and Keaveney $\mathrm{K}$ (2012b) Placing neoliberalism: the rise and fall of Ireland's celtic tiger. Environment and Planning A 44: 1302-1326

Kitchin R and Sidaway J (2006) Geography's strategies. Professional Geographer 58(4): 485-491.

Kittler FA (1999) Gramophone, Film, Typewriter. Stanford, CA: Stanford University Press.

Kjellberg S (2009) Blogs as interfaces between several worlds: a case study of the swedish academic blogosphere. Human IT 10(3): 1-45.

Kruase M (2007) Practicing authorship: the case of Brecht's plays Monika Krause. In: C Calhoun and R Sennett (eds) Practicing Culture. Oxford, UK: Routledge.

Livingstone D (1992) The Geographical Tradition. Oxford, UK: Blackwell.

Macgilchrist F and Böhmig I (2012) Blogs, genes and immigration: online media and minimal politics. Media, Culture and Society 34(1): 83-100.
Madge C, Meek J, Wellens J, and Hooley T (2009) Facebook, social integration and informal learning at university: 'it is more for socialising and talking to friends about work than for actually doing work'. Learning, Media and Technology 34(2): 141-155.

Marchart O (2010) Die politische Differenz [The Political Difference]. Berlin, Germany: Suhrkamp.

Martin R (2001) Geography and public policy: the case of the missing agenda. Progress in Human Geography 25: 189-210.

Massey D (2000) Practising political relevance. Transactions of the Institute of British Geographers 24: 131-134.

McFadden J and Berkowitz B (2009) Community 2.0: How the disruption of media and government has birthed a smarter community. Building a Smarter Planet blog. Available at: http://asmarterplanet.com/blog/ 2009/12/community-2-0-how-the-disruption-of-media-and-government-has-birthed-a-smarter-community.html (accessed 12 January 2013).

McGuirk P and O'Neill P (2012) Critical geographies with the state: the problem of social vulnerability and the politics of engaged research. Antipode 44: 1374-1394.

Murphy AB (2006) Enhancing geography's role in public debate. Annals of the Association of American Geographers 96(1): 1-13.

Nietzsche F (2005) Letter toward the end of February. In: G Colli and M Montinari (eds) F. Nietzsche Briefwechsel: Kritische Gesamtausgabe (p. 172), Berlin, Germany : de Gruyter Verlag.

Pain R and Kindon S (2007) Participatory geographies. Environment and Planning A 39: 2807-2812.

Pain R, Kesby M, and Askins K (2011) Geographies of impact: power, participation and potential. Area 43: 183-188.

Pain R, Kesby M, and Askins K (2012) The politics of social justice in neoliberal times: a reply to Slater. Area 44(1): 120-123.

Participatory Geographies Research Group (2012) Communifesto for fuller geographies: towards mutual security, http://radicalantipode.files.wordpress.com/ 2012/10/communifesto-for-fuller-geographies.pdf (accessed 12 January 2013).

Peck J (1999) Grey geography? Transactions of the Institute of British Geographers 24: 131-136.

Price DH (2010) Blogging anthropology: savage minds, zero anthropology, and AAA blogs. American Anthropologist 112(1): 140-142. 
Prince HC (1971) 'America! America?' views on a melting pot 1. questions of social relevance. Area 3: 150-153.

Slater T (2012) Impacted geographers: a response to Pain, Kesby and Askins. Area 44(1): 117-119.

Staeheli LA and Mitchell D (2005) The complex politics of relevance in geography. Annals of the Association of American Geographers 95: 357-372.

Terras M (2012) The verdict: is blogging or tweeting about research papers worth it?, http://melissaterras. blogspot.co.uk/2012/04/is-blogging-and-tweeting-about-research.html (accessed 9 May 2012).

Titley G (2012) Budgetjam! A communications intervention in the political-economic crisis in Ireland. Journalism 14(2): 292-306.
Ward K (2005) Geography and public policy: a recent history of 'policy relevance'. Progress in Human Geography 29(3): 310-319.

Ward K (2006) Geography and public policy: towards public geographies. Progress in Human Geography 30(4): 495-503.

Ward K (2007) Geography and public policy: activist, participatory and policy geographies. Progress in Human Geography 31: 695-705.

Wellman B and Haythornthwaite C (ed) (2007) The Internet in Everyday Life. Chichester, UK: Wiley, 2007.

Woods M and Gardner G (2011) Applied policy research and critical human geography: some reflections on swimming in murky waters. Dialogues in Human Geography 1: 198-214. 